\title{
Effect of iron supplementation during pregnancy on the behaviour of children at early school age: long-term follow-up of a randomised controlled trial
}

\author{
Annie G. Parsons ${ }^{1,2}$, Shao J. Zhou ${ }^{1}$, Nicola J. Spurrier ${ }^{3}$ and Maria Makrides ${ }^{1,2 *}$ \\ ${ }^{1}$ Child Nutrition Research Centre, Flinders Medical Centre and Women's \& Children's Hospital, Child Health Research Institute, \\ 72 King William Road, North Adelaide, SA 5006, Australia \\ ${ }^{2}$ Discipline of Paediatrics, University of Adelaide, Women's \& Children's Hospital, 72 King William Road, North Adelaide, \\ SA 5006, Australia \\ ${ }^{3}$ Department of Paediatrics and Child Health, Flinders University and Flinders Medical Centre, Bedford Park, SA 5042, Australia \\ (Received 30 March 2007 - Revised 3 August 2007 - Accepted 21 September 2007 - First published online 13 November 2007)
}

\begin{abstract}
Although routine Fe supplementation in pregnancy is a common practice, its clinical benefits or risks are uncertain. Children born to mothers in the Fe group in a trial of $\mathrm{Fe}$ supplementation in pregnancy have been found to have a significantly higher risk of abnormal behaviour at 4 years of age than those born to mothers in the placebo group. The objective of the present study therefore was to determine whether Fe supplementation in pregnancy influences child behaviour at early school age. The study was a follow-up of children at $6-8$ years of age after women ( $n$ 430) were randomly allocated to receive a daily Fe supplement $(20 \mathrm{mg})$ or placebo from 20 weeks gestation until delivery. The supplement reduced the incidence of Fe-deficiency anaemia at delivery from $9 \%$ to $1 \%$. Child behaviour and temperament were assessed using the Strengths and Difficulties Questionnaire and the Short Temperament Scale for Children. Of the children, $264(61 \%)$ participated in the follow-up. Mean behaviour and temperament scores and the proportion of parent-rated and teacher-rated abnormal total difficulties scores did not differ between the Fe and placebo groups. However, the incidence of children with an abnormal teacher-rated peer problems subscale score was higher in the Fe group (eleven of 112 subjects; $8 \%$ ) than in the placebo group (three of 113 subjects; $2 \%$ ); the relative risk was $3.70(95 \%$ CI $1 \cdot 06,12 \cdot 91 ; P=0 \cdot 026)$. We conclude that prenatal Fe supplementation had no consistent effect on child behaviour at early school age in this study population. Further investigation regarding the long-term effects of this common practice is warranted.
\end{abstract}

Iron supplementation: Pregnancy: Child behaviour: Industrialised countries

Routine Fe supplementation in pregnancy is a common practice to prevent Fe deficiency and Fe-deficiency anaemia, although expert opinion on this practice is divided. While pregnant women in the $\mathrm{USA}^{(1)}$ are routinely advised to take Fe supplements of $30-60 \mathrm{mg} / \mathrm{d}$, the policy in Australia ${ }^{(2)}$ and the $\mathrm{UK}^{(3)}$ is to screen pregnant women for anaemia and only treat those with Fe-deficiency anaemia. A reason for this is that although $\mathrm{Fe}$ supplementation in pregnancy improves maternal $\mathrm{Fe}$ status, there is a paucity of evidence of a clear clinical benefit for mothers ${ }^{(4,5)}$. The long-term effects of routine Fe supplementation on child development is also unclear ${ }^{(4,5)}$. We recently published a 4-year follow-up of the Adelaide Mothers' and Babies' Iron Trial (AMBIT), the first human intervention trial designed specifically to assess the effect of routine low-dose Fe supplementation $(20 \mathrm{mg} / \mathrm{d})$ on childhood intelligence quotient (IQ) and behaviour ${ }^{(6)}$. Our findings indicated that routine $\mathrm{Fe}$ supplementation in pregnancy had no effect on IQ at 4 years. There was, however, a higher incidence of abnormal behaviour reported by parents of children in the $\mathrm{Fe}$ group than in the placebo group ${ }^{(6)}$. Although this may have been a chance finding, the possibility that it reflects a true adverse effect of routine $\mathrm{Fe}$ supplementation in pregnancy in well-nourished populations cannot be overlooked. Animal studies have highlighted that both inadequate $\mathrm{Fe}$ nutrition in pregnancy and prenatal $\mathrm{Fe}$ overload are associated with persistent behavioural changes in offspring ${ }^{(7-9)}$ regardless of later $\mathrm{Fe}$ status or later Fe supplementation ${ }^{(7)}$. The aim of the present study was to assess whether routine Fe supplementation in pregnancy in a well-nourished population affects child behaviour at early school age through further follow-up of the children born in the AMBIT.

\section{Subjects and methods}

Participants

Participants were children born in the AMBIT, a doubleblind randomised controlled trial of $\mathrm{Fe}$ supplementation in pregnancy ${ }^{(10)}$. The original trial was conducted between 1997 and 1999. Four hundred and thirty non-anaemic pregnant

Abbreviations: AMBIT, Adelaide Mothers' and Babies' Iron Trial; IQ, intelligence quotient; SDQ, Strengths and Difficulties Questionnaire; STSC, Short Temperament Scale for Children.

* Corresponding author: Associate Professor Maria Makrides, fax +618 8161 8228, email maria.makrides@cywhs.sa.gov.au 
women receiving antenatal care at the Children, Youth and Women's Health Services in Adelaide, Australia were recruited to participate. Women were randomly allocated to receive either low-dose $\mathrm{Fe}(20 \mathrm{mg} / \mathrm{d})$ or placebo from 20 weeks gestation until delivery. The low-dose supplement was designed to increase Fe intake to the recommended dietary intake for pregnant women in Australia at that time, $22-36 \mathrm{mg} / \mathrm{d}^{(11)}$. The compliance rate was $86 \%$ for both groups and the dietary intake of $\mathrm{Fe}$ during pregnancy also did not differ between groups (13.0 (SD 5.4) mg/d in the $\mathrm{Fe}$ group and 13.6 (SD 5.4) $\mathrm{mg} / \mathrm{d}$ in the control group; $P=0 \cdot 299)^{(10)}$. The incidence of Fe-deficiency anaemia and Fe deficiency in women at delivery was significantly lower in the Fe group than in the placebo group (Table 1). The present follow-up was conducted between April and November 2006 when the children born in the AMBIT were between 6 and 8 years old. Participation in the 4 -year follow-up ${ }^{(6)}$ was not a prerequisite for participation in this school-age follow-up and an attempt was made to contact all mothers and children enrolled in the original study. In the present paper children are referred to as belonging to the Fe or the placebo group according to their mother's group allocation in the AMBIT. The present study was approved by the Children, Youth and Women's Health Services Research Ethics Committee. Informed consent was obtained from the families of all participants.

\section{Assessments}

The primary outcome was child behaviour assessed using parentrated and teacher-rated versions of the Strengths and Difficulties Questionnaire (SDQ) ${ }^{(12)}$ for 4-10-year-olds. The SDQ is an internationally validated brief screening measure used to assess behavioural problems ${ }^{(13)}$. It was chosen as the primary outcome because it was used to assess behaviour in the 4-year AMBIT follow-up in which a higher incidence of total difficult behaviours was reported by parents in the Fe group compared with control ${ }^{(6)}$. The SDQ has five subscales (conduct problems, peer problems, hyperactivity, emotional symptoms and prosocial behaviour)

Table 1. The demographic characteristics of participating families

\begin{tabular}{|c|c|c|c|c|c|}
\hline & \multicolumn{4}{|c|}{ Mother's group assignment in AMBIT } & \multirow[b]{3}{*}{$P$} \\
\hline & \multicolumn{2}{|c|}{$\mathrm{Fe}(n 132)$} & \multicolumn{2}{|c|}{ Placebo ( $n$ 132) } & \\
\hline & $n$ & $\%$ & $n$ & $\%$ & \\
\hline \multicolumn{6}{|l|}{ Maternal characteristics } \\
\hline Age at enrolment in AMBIT (years) & & & & & 0.731 \\
\hline Mean & \multicolumn{2}{|c|}{$29 \cdot 3$} & \multicolumn{2}{|c|}{$29 \cdot 5$} & \\
\hline SD & \multicolumn{2}{|c|}{4.8} & \multicolumn{2}{|c|}{4.7} & \\
\hline Education level & & & & & 0.925 \\
\hline$\leq 12$ years & 92 & 70 & 92 & 70 & \\
\hline Diploma or degree & 40 & 30 & 39 & 30 & \\
\hline Occupation score ${ }^{*}$ & & & & & 0.232 \\
\hline Mean & \multicolumn{2}{|c|}{4.9} & \multicolumn{2}{|c|}{$4 \cdot 8$} & \\
\hline SD & \multicolumn{2}{|c|}{0.8} & \multicolumn{2}{|c|}{0.9} & \\
\hline Smoked in pregnancy & 22 & 17 & 19 & 14 & 0.610 \\
\hline \multicolumn{6}{|l|}{ Fe status at birth $(n / N)$} \\
\hline ID & $36 / 122$ & 30 & $64 / 119$ & 54 & $<0.001$ \\
\hline IDA & $1 / 124$ & 1 & $11 / 125$ & 9 & 0.003 \\
\hline \multicolumn{6}{|l|}{ Characteristics of children } \\
\hline Age (years) & & & & & 0.277 \\
\hline Mean & \multicolumn{2}{|c|}{$7 \cdot 5$} & \multicolumn{2}{|c|}{$7 \cdot 6$} & \\
\hline SD & \multicolumn{2}{|c|}{0.4} & \multicolumn{2}{|c|}{0.4} & \\
\hline Male sex & 74 & 56 & 62 & 47 & 0.139 \\
\hline Birth order & & & & & 0.967 \\
\hline 1 & 63 & 48 & 65 & 49 & \\
\hline 2 & 49 & 37 & 48 & 36 & \\
\hline$\geq 3$ & 20 & 15 & 19 & 14 & \\
\hline Gestational age at birth (weeks) & & & & & $0 \cdot 208$ \\
\hline Mean & 39 . & & & & \\
\hline SD & 1.9 & & & & \\
\hline Breastfed $\geq 6$ months & 57 & 44 & 58 & 45 & 0.857 \\
\hline \multicolumn{6}{|l|}{ Recent life events } \\
\hline Number of events in the last year & & & & & 0.120 \\
\hline Mean & \multicolumn{2}{|c|}{$2 \cdot 1$} & \multicolumn{2}{|c|}{$2 \cdot 6$} & \\
\hline SD & \multicolumn{2}{|c|}{$2 \cdot 2$} & \multicolumn{2}{|c|}{2.5} & \\
\hline Number of events having an effect & & & & & 0.454 \\
\hline Mean & \multicolumn{2}{|c|}{0.9} & \multicolumn{2}{|c|}{$1 \cdot 0$} & \\
\hline SD & 1.4 & & & & \\
\hline General family functioning score & & & & & 0.053 \\
\hline Mean & 1.5 & & & & \\
\hline SD & 0.5 & & & & \\
\hline
\end{tabular}

AMBIT, Adelaide Mothers' and Babies' Iron Trial; ID, Fe deficiency (defined as ferritin $<12 \mu \mathrm{g} / \mathrm{l}$ ); IDA, Fedeficiency anaemia (defined as $\mathrm{Hb}<110 \mathrm{~g} / \mathrm{l}$ and ferritin $<12 \mu \mathrm{g} / \mathrm{l}$ ).

${ }^{*}$ Ranked according to the scale by Daniel ${ }^{(25)}$. The higher the score, the lower the skilled occupation. 
in addition to a combined total difficulties scale. Total difficulties scores and subscale scores are defined as 'normal' and 'abnormal' according to SDQ cut-offs ${ }^{(14)}$. The questionnaire has moderateto-strong internal reliability, test-retest reliability and external validity $^{(13,15)}$. In addition to the SDQ, parents were also asked whether they had ever consulted a healthcare professional about difficulties with their child's behaviour and, if they had, to provide details of the consultation.

The secondary outcome was child temperament assessed using the parent-rated Short Temperament Scale for Children (STSC) ${ }^{(16)}$. This was included to support the SDQ because temperament reflects behavioural style. Children with a history of behavioural problems have more consistently difficult temperaments than their counterparts without behavioural problems $^{(16)}$. The STSC has four subscales (approach, persistence, rhythmicity and inflexibility) in addition to a total easydifficult temperament scale. The STSC has strong internal consistency and was developed after factor analysis of the longer Childhood Temperament Questionnaire ${ }^{(17)}$. A total easy-difficult temperament score of $>1$ SD above the population mean is indicative of a difficult temperament ${ }^{(16)}$.

To assess the effect of potential covariates, parents were also asked to complete two brief measures of risk factors for behavioural problems in children. A Recent Life Events questionnaire ${ }^{(18)}$ was used to assess the number and impact of life events in the family, while the General Functioning Subscale of the McMaster Family Assessment Device ${ }^{(19)}$ was used to assess the healthiness of the family unit. Information regarding sex, gestational age at birth, birth order, duration of breast-feeding, maternal smoking in pregnancy, parental education and occupation were extracted from the original AMBIT dataset ${ }^{(10)}$.
Research staff involved in data collection were blinded to the group assignment until all primary analyses were completed. Mothers had the opportunity to learn their group allocation in the AMBIT at the conclusion of the 4-year follow-up ${ }^{(6)}$ but were not reinformed during the present follow-up.

\section{Statistical analysis}

The data were analysed using SPSS software (version 10.0.1; SPSS Inc., Chicago, IL, USA). The primary analyses were based on intention to treat. Mean scores for parent-rated child behaviour, child temperament and teacher-rated child behaviour were compared between the $\mathrm{Fe}$ and placebo groups using independent samples $t$ tests. Differences between categorical variables such as SDQ scores dichotomised to 'normal' and 'abnormal' were compared using $\chi^{2}$ tests. Statistical significance was set at a $P$ value $<0.05$ for all statistical tests. Regression analyses were conducted to examine the influence of potential covariates on group comparisons. Selection of potential covariates was based on independent predictors cited in the literature as influencing child behaviour and those maternal and child characteristics where the $P$ value for comparison between groups was 0.2 or less.

\section{Results}

Characteristics of the participants

A total of $61 \%$ (264 out of 433 subjects) of the children born in the AMBIT were assessed at follow-up (Fig. 1). A total of $89 \%$ ( 236 out of 264 subjects) of the children who participated

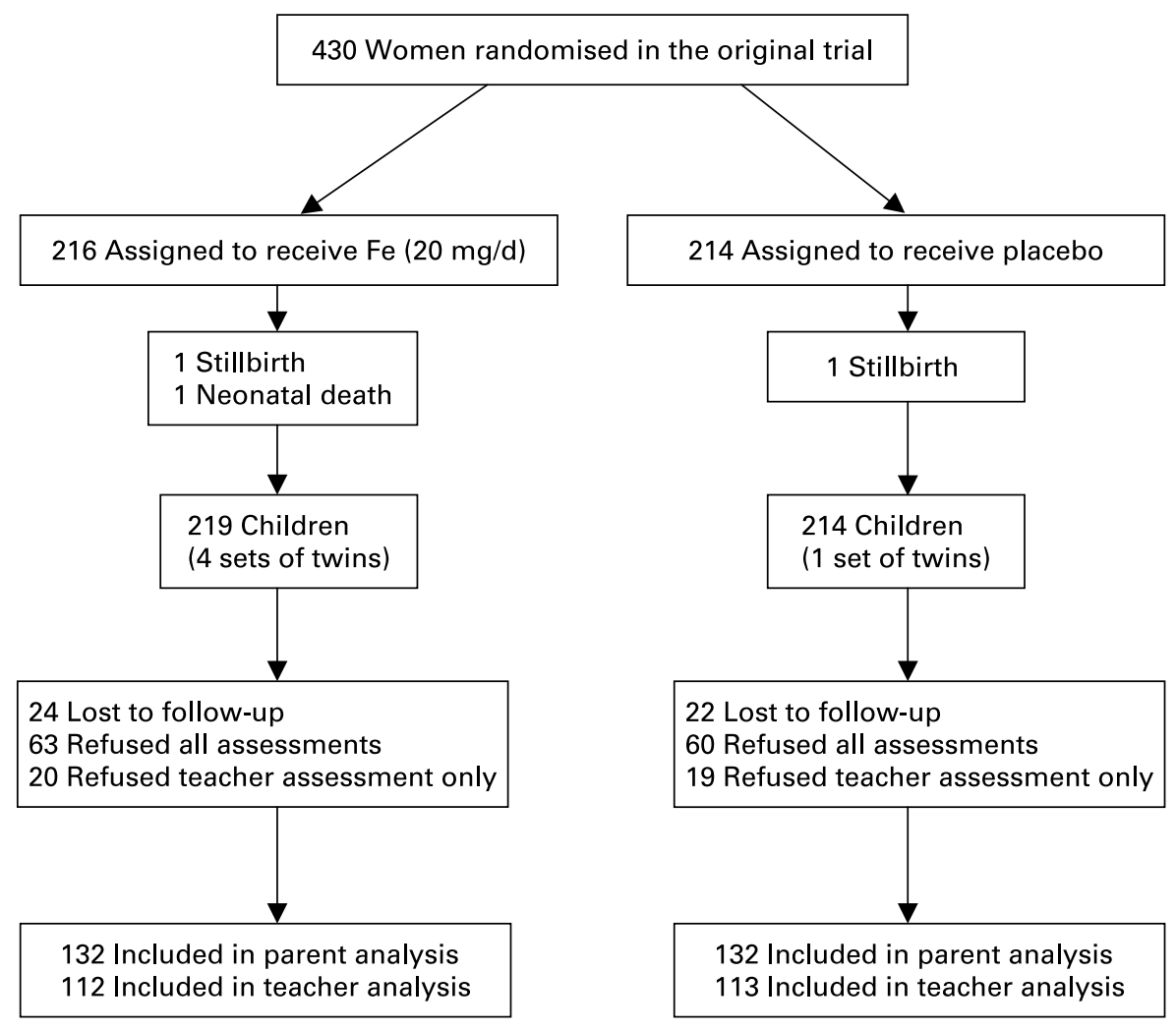

Fig. 1. Flow diagram of the original Fe trial and the early school-age follow-up. 
in this follow-up also participated in the 4-year follow-up. All children had at least 1 year of schooling at the time of assessment because children start school at age 5 years in Adelaide where the study was conducted. The social and demographic characteristics of participating families did not differ between the $\mathrm{Fe}$ and placebo groups (Table 1). The difference in maternal $\mathrm{Fe}$ status at the conclusion of the original trial (at birth) between the Fe and placebo groups remained significant among follow-up participants. There were significant differences between the socio-demographic characteristics of participants and non-participants. Mothers of children who did not participate were generally younger than participating mothers $(P=0.016)$. They were also more likely to have a lower skilled occupation and to have smoked during pregnancy, and less likely to have breastfed their child, than the mothers of participating children $(P<0.05$ for all $)$.

\section{Child behaviour}

The mean scores for parent-rated and teacher-rated SDQ scores did not differ between the $\mathrm{Fe}$ and placebo groups (Table 2). There was no difference in the proportion of children with abnormal parent-rated behaviour scores in the two groups (Table 3). There was a higher incidence of abnormal teacher-rated peer problems scores in the $\mathrm{Fe}$ group than the placebo group (Table 3). The relative risk was 3.70 (Table 3). Adjustment for potential covariates including family functioning and sex of the child did not affect the statistical significance of any analyses for the behaviour outcome. There were strong positive correlations between parent-rated and teacher-rated total difficulties scores $(r 0.587 ; P<0.001)$ as well as parent-rated total difficulties scores between the 4-year follow-up ${ }^{(6)}$ and the present follow-up ( $r$ 0.593; $P<0 \cdot 001)$. Among the thirty-six children who had an abnormal parent-rated total difficulties score at the 4-year followup $^{(6)}$, twenty-five of them participated in the present study and ten of the twenty-five remained abnormal. There was no significant association between a behavioural consultation and group allocation (twenty-seven of $132(20 \%)$ children in the Fe group compared with twenty-one of $132(16 \%)$ children in the placebo group; $P=0 \cdot 353)$. There were significant differences between the behaviour and temperament scores of those children who had a behavioural consultation and those who had not. Children who had had a consultation for their behaviour had higher parent-rated total difficulties scores than those who had not (16.0 (SD 5.9) compared with 7.3 (SD 4.9) for the parent-rated SDQ; mean difference 8.74 (95\% CI 7, 11); $P<0.001)$; they also had higher teacherrated total difficulties scores than those who had not had a consultation (13.0 (SD 7.9) compared with 5.3 (SD 7.4) for the teacher-rated SDQ; mean difference 10.25 (95\% CI 5, 10); $P<0 \cdot 001)$.

\section{Child temperament}

There was no difference between either mean temperament scores or the proportion of children with difficult temperament scores in the $\mathrm{Fe}$ and placebo groups (Tables 4 and 5). There was a strong correlation between parent-rated behaviour total difficulties scores and total temperament scores ( $r$ 0.637; $P<0 \cdot 001)$. Children who had consulted a health professional for behavioural problems had more difficult temperament ratings than those who had not (3.5 (SD 0.6) compared with 2.8 (SD 0.5); mean difference 0.74 (95\% CI 0.6, 0.9); $P<0.001$ ).

\section{Discussion}

This is the first human intervention trial to assess the long-term effects of routine $\mathrm{Fe}$ supplementation in pregnancy on child behaviour and development. The present results demonstrate that Fe supplementation in pregnancy had no clear beneficial or adverse effect on parental reports of child behaviour and temperament when the children were $6-8$ years of age. There was also no difference in the incidence of teacher-rated total abnormal behaviour scores in the two groups. However, significantly

Table 2. Parent-rated and teacher-rated behaviour scores

(Mean values and standard deviations)

\begin{tabular}{|c|c|c|c|c|c|c|c|}
\hline & \multicolumn{4}{|c|}{ Mother's group assignment in AMBIT } & \multirow[b]{3}{*}{ MD } & \multirow[b]{3}{*}{$95 \% \mathrm{Cl}$} & \multirow[b]{3}{*}{$P$} \\
\hline & \multicolumn{2}{|c|}{$\mathrm{Fe}$} & \multicolumn{2}{|c|}{ Placebo } & & & \\
\hline & Mean & SD & Mean & SD & & & \\
\hline Parent-rated SDQ $(n)$ & \multicolumn{2}{|c|}{132} & \multicolumn{2}{|c|}{132} & & & \\
\hline Emotion & $2 \cdot 0$ & $2 \cdot 1^{2}$ & $2 \cdot 3$ & $2 \cdot 1$ & -0.32 & $-0.83,0 \cdot 18$ & 0.212 \\
\hline Conduct & $1 \cdot 7$ & $1 \cdot 8$ & 1.9 & 1.9 & -0.23 & $-0.67,0.21$ & 0.301 \\
\hline Hyperactivity & $3 \cdot 6$ & $2 \cdot 9$ & $3 \cdot 6$ & $2 \cdot 6$ & -0.05 & $-0.73,0.63$ & 0.883 \\
\hline Peer problems & 1.4 & 1.6 & 1.4 & 1.6 & -0.02 & $-0 \cdot 40,0 \cdot 37$ & 0.939 \\
\hline Prosocial behaviour & $8 \cdot 1$ & 1.8 & $8 \cdot 0$ & 1.9 & -0.06 & $-0.38,0.50$ & 0.787 \\
\hline Total difficulties score & $8 \cdot 6$ & $6 \cdot 3$ & $9 \cdot 2$ & $5 \cdot 9$ & -0.62 & $-2 \cdot 10,0 \cdot 87$ & 0.412 \\
\hline Teacher-rated SDQ $(n)$ & \multicolumn{2}{|c|}{112} & \multicolumn{2}{|c|}{113} & & & \\
\hline Emotion & 1.4 & 1.8 & $1 \cdot 7$ & $2 \cdot 2$ & -0.31 & $-0.83,0 \cdot 21$ & 0.239 \\
\hline Conduct & 1.0 & 1.9 & 0.9 & 1.5 & -0.07 & $-0.37,0.52$ & 0.755 \\
\hline Hyperactivity & $2 \cdot 9$ & $2 \cdot 9$ & $3 \cdot 0$ & $3 \cdot 2$ & -0.17 & $-0.97,0.64$ & 0.683 \\
\hline Peer problems & 1.4 & 1.9 & 1.2 & 1.4 & -0.25 & $-0.18,0.69$ & 0.256 \\
\hline Prosocial behaviour & $7 \cdot 9$ & $2 \cdot 2$ & $7 \cdot 7$ & $2 \cdot 3$ & -0.15 & $-0.44,0.74$ & 0.615 \\
\hline Total difficulties score & $6 \cdot 7$ & $6 \cdot 2$ & $6 \cdot 8$ & $6 \cdot 3$ & -0.16 & $-1 \cdot 80,1 \cdot 48$ & 0.851 \\
\hline
\end{tabular}

AMBIT, Adelaide Mothers' and Babies' Iron Trial; MD, mean difference; SDQ, Strengths and Difficulties Questionnaire. 
Table 3. Proportion of children with abnormal behaviour ratings on the Strengths and Difficulties Questionnaire (SDQ)

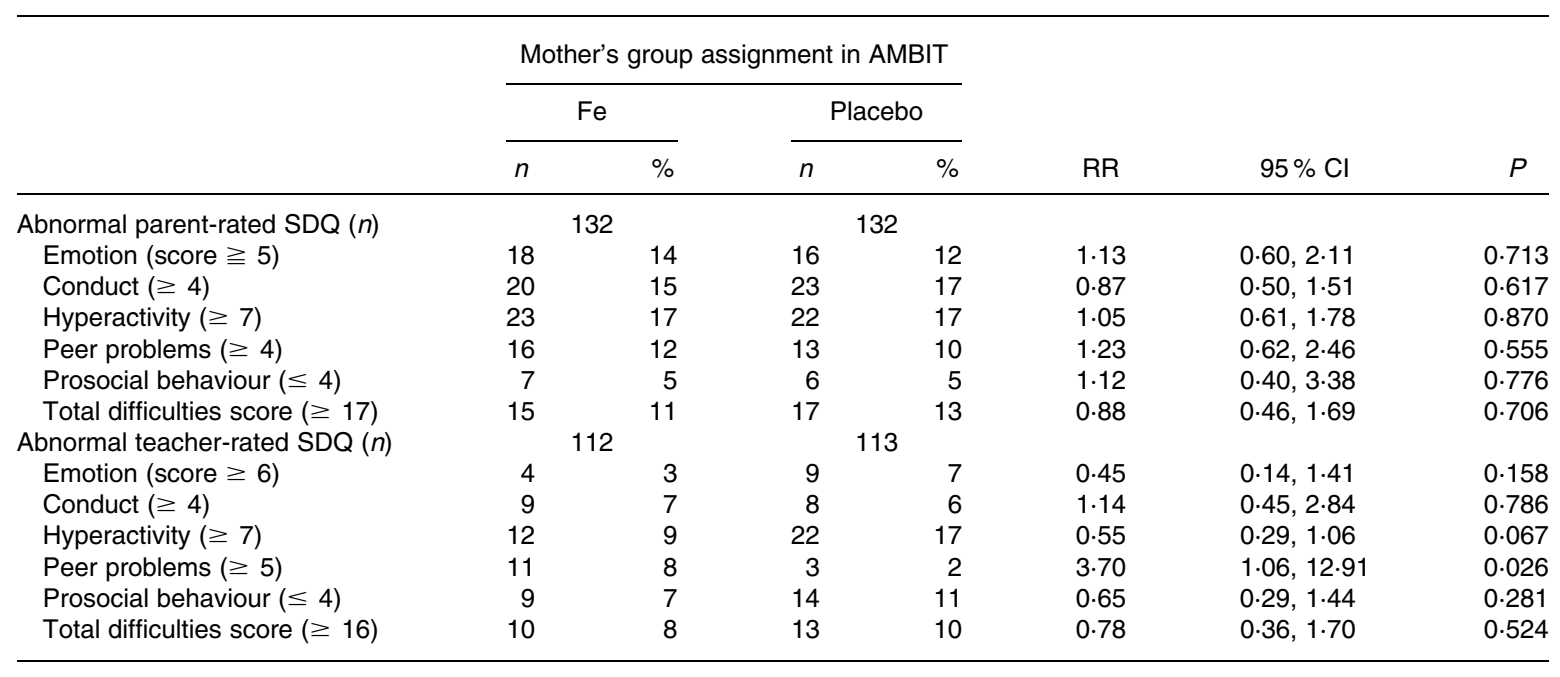

AMBIT, Adelaide Mothers' and Babies' Iron Trial; RR, relative risk.

more children in the Fe group had an abnormal teacher-rated peer problems score than in the placebo group.

Although the majority of data collected in the present study from multiple assessments indicate no effect of Fe supplementation in pregnancy of childhood behaviour at early school age, our single report of a higher incidence of abnormal peer problems rated by teachers in the $\mathrm{Fe}$ group deserves some attention because the effect is consistent with our earlier observations when the children were 4 years of age ${ }^{(6)}$. The only other human study to suggest that a high Fe supply to the fetus may adversely affect early childhood development was a cohort study involving largely small-for-gestational-age infants ${ }^{(20)}$. They reported that children with cord serum ferritin levels in the highest quartile scored lower on developmental tests including Full Scale IQ than children with cord serum ferritin levels in the two middle quartiles. Children with cord ferritin in the lowest quartile also scored lower than the median quartiles on some measures. While the investigators suggested that ferritin levels in the highest quartile may have been falsely elevated due to maternal infection, it is plausible that the high cord ferritin levels (high Fe status) adversely affected child development. These data are supported by an animal study that showed excessive Fe exposure during the neonatal period altered long-term neurobehavioural outcome, including motor behaviour and radial arm maze learning ${ }^{(9)}$.
On the other hand, the incidence of abnormal teacher-rated peer problems was relatively small and it is not possible to exclude that this is a chance effect because of limited sample size. The difference in teacher-rated abnormal peer problems scores was not reflected in the corresponding peer problems subscale in the parent-rated SDQ. The number of teacher questionnaires returned was less than the number of parent questionnaires and it is possible that an increased teacher response rate might have reduced the variance in scores to the level of the parent-rated scores. Conversely, it is likely that teachers witness a range of peer interactions that parents are not privy to, and this may be why the ratings vary between the two versions of the SDQ. When multiple informants are used, clinician and researcher assessments can differ depending on the information sources used in assessment and the weight given to information from different sources where disagreement exists ${ }^{(21)}$. However, Goodman ${ }^{(13)}$ reported better inter-rater correlations between the parent and teacher versions of the SDQ than for other behavioural measures such as the Child Behaviour Checklist.

The parent-rated SDQ and STSC scores of the children reflect normative data for the Australian population ${ }^{(15,17)}$. The parentrated SDQ total difficulties score and the STSC easy-difficult temperament score correlated well, reflecting consistency in parent answers and increasing confidence in the ability of

Table 4. Child temperament: parent-rated temperament score (Mean values and standard deviations)

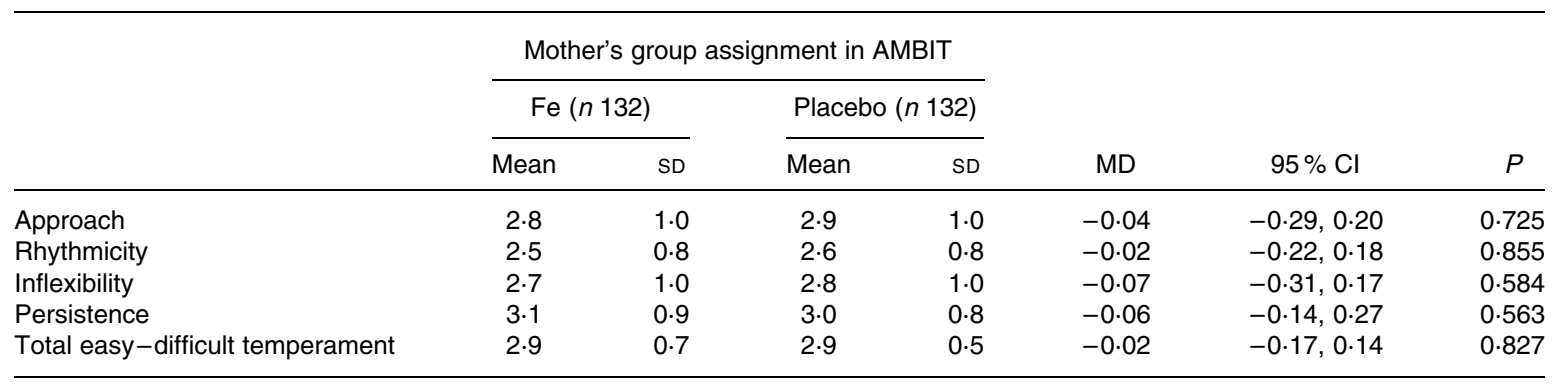

AMBIT, Adelaide Mothers' and Babies' Iron Trial; MD, mean difference. 
Table 5. Child temperament: difficult temperament*

\begin{tabular}{|c|c|c|c|c|c|c|c|}
\hline & \multicolumn{4}{|c|}{ Mother's group assignment in AMBIT } & \multirow[b]{3}{*}{$\mathrm{RR}$} & \multirow[b]{3}{*}{$95 \% \mathrm{Cl}$} & \multirow[b]{3}{*}{$P$} \\
\hline & \multicolumn{2}{|c|}{$\mathrm{Fe}(n 132)$} & \multicolumn{2}{|c|}{ Placebo (n 132) } & & & \\
\hline & $n$ & $\%$ & $n$ & $\%$ & & & \\
\hline Approach & 21 & 16 & 19 & 14 & $1 \cdot 11$ & $0.62,1.96$ & 0.731 \\
\hline Rhythmicity & 23 & 17 & 24 & 18 & 0.96 & $0.57,1.61$ & 0.872 \\
\hline Inflexibility & 24 & 18 & 19 & 14 & 1.26 & $0.73,2 \cdot 19$ & 0.405 \\
\hline Persistence & 29 & 22 & 19 & 14 & 1.53 & $0.90,2.58$ & 0.111 \\
\hline Total easy-difficult temperament & 23 & 17 & 20 & 15 & $1 \cdot 15$ & $0.66,1.99$ & 0.617 \\
\hline
\end{tabular}

AMBIT, Adelaide Mothers' and Babies' Iron Trial; RR, relative risk.

${ }^{*}$ Defined as a score $1 \mathrm{SD}$ above the sample mean ${ }^{(16)}$

these measures to identify common themes in both behaviour and temperament. Adjustment for the difference in potential confounding factors of behaviour between groups including family functioning did not alter the study findings.

A potential limitation of the present study was a relatively high attrition rate although it is better or comparable with that of other long-term follow-up studies of perinatal nutrition interventions ${ }^{(22,23)}$. There were also significant differences between the socio-demographic characteristics of participants and non-participants. Similar differences have also been documented in other long-term nutritional studies ${ }^{(24)}$. Women with a young maternal age, low education level, who smoke during pregnancy or do not breastfeed their child are less likely to comply with the study treatment and more likely to withdraw or be lost to follow-up ${ }^{(24)}$. Despite these factors, the present study had high internal validity. Participation rates were equal across the two groups, there were no differences in the baseline characteristics of the groups and the effect of the intervention (the incidence of $\mathrm{Fe}$ deficiency and $\mathrm{Fe}$ deficiency anaemia at delivery) remained significant and equivalent in size to that seen in the original report ${ }^{(10)}$. These points highlight the overall strength of the present report as a long-term follow-up of a randomised controlled trial designed to investigate causal relationships.

In summary, our data suggest that routine Fe supplementation in pregnancy in an otherwise well-nourished population has no effect on behaviour and may even have a negative influence. However, our findings may not generalise to other populations where Fe deficiency in pregnancy is more severe. Our earlier follow-up of the same children showed no effect on $\mathrm{IQ}^{(6)}$, and other randomised controlled trials of prophylactic $\mathrm{Fe}$ supplementation in pregnancy suggest that Fe does not improve pregnancy outcomes ${ }^{(4,5)}$. Taken together, these data indicate that routine Fe supplementation of wellnourished women in pregnancy has no detectable benefit in terms of clinical measures beyond improved maternal Fe status and raise the possibility of an adverse outcome on child behaviour. It is therefore prudent that this widespread practice be re-evaluated in industrialised countries.

\section{Acknowledgements}

We thank the families who participated in the study and the Child Health Research Institute for supporting the study. We thank Heather Garreffa, Vanessa Derecki and Jenni Scambiatterra for their administrative support.
All authors contributed to the study design. Under the supervision of M. M., N. J. S. and S. J. Z. A., G. P. collected and analysed the data. A. G. P. wrote the manuscript with contributions from all co-authors. M. M. occasionally provides advice to manufacturers of prenatal nutrition supplements. Other authors had no known conflict of interest.

M. M. was supported by a National Health \& Medical Research Council Senior Research Fellowship (ID 298902). The Fe and placebo tablets used in the trial were manufactured and donated by Soul Pattinson Manufacturing (Kingsgrove, NSW, Australia). The funding organizations and Soul Pattison Manufacturing had no role in the design and conduct of the study, the analysis and interpretation of the data, or the preparation, review and approval of the manuscript.

\section{References}

1. Centers for Disease Control and Prevention (1998) Recommendations to prevent and control iron deficiency in the United States. MMWR 47, 1-29.

2. Australian Iron Status Advisory Panel (2001) Iron Status and Pregnancy: Current Practice. Recommended Guidelines. http:// www.ironpanel.org.au/AIS/AISdocs/pregdocs/preg36.html (accessed July 2007).

3. National Collaborating Centre for Women's and Children's Health (2003) Routine Care for the Healthy Pregnant Women: Clinical Guideline, p. 9. London: National Institute for Clinical Excellence.

4. US Preventive Services Task Force (1993) Routine iron supplementation during pregnancy. JAMA 270, 2848-2854.

5. Mahomed K (2003) Iron supplementation in pregnancy. The Cochrane Database of Systematic Reviews 2003, issue 2, CD000117. http://www.mrw.interscience.wiley.com/cochrane/ clsysrev/articles/CD000117/frame.html

6. Zhou SJ, Gibson RA, Crowther CA, Baghurst PAH \& Makrides M (2006) Effect of iron supplementation in pregnancy on IQ and behavior of children at 4 years: long term follow up of a randomized controlled trial. Am J Clin Nutr 83, 1112-1117.

7. Kwik-Uribe CL, Golub MS \& Keen CL (2000) Chronic marginal iron intakes during early development in mice alter brain iron concentrations and behavior despite postnatal iron supplementation. J Nutr 130, 2040-2048.

8. deUngria M, Rao R, Wobken JD, Luciana M, Nelson CA \& Georgieff MK (2000) Perinatal iron deficiency decreases cytochrome c oxidase (CytOx) activity in selected regions of neonatal rat brain. Pediatr Res 48, 169-176.

9. Fredriksson A, Schroder N, Eriksson P, Izquierdo I \& Archer T (1999) Neonatal iron exposure induces neurobehavioral dysfunctions in adult mice. Toxicol Appl Pharmacol 159, 25-30. 
10. Makrides M, Crowther CA, Gibson RA, Gibson RS \& Skeaff CM (2003) Efficacy and tolerability of low-dose iron supplements during pregnancy: a randomized controlled trial. Am J Clin Nutr 78, 145-153.

11. National Health and Medical Research Council (1991) Recommended Dietary Intakes for Use in Australia. Canberra: Australian Government Publishing Service.

12. Goodman R (2006) Strengths and Difficulties Questionnaire version February 2006. http://sdqinfo.com/ba3.html (accessed February 2006).

13. Goodman R (2001) Psychometric properties of the Strengths and Difficulties Questionnaire. J Am Acad Child Adolesc Psychiatry 40, 1337-1345.

14. Goodman R (2006) Scoring the Informant-Rated Strengths and Difficulties Questionnaire, version February 2006. http://www. sdqinfo.com/ScoreSheets/el.pdf (accessed February 2006).

15. Hawes DJ \& Dadds MR (2004) Australian data and psychometric properties of the Strengths and Difficulties Questionnaire. Aust N Z J Psychiatry 38, 644-651.

16. Prior M, Sanson A, Smart D \& Oberklaid F (2000) Pathways from Infancy to Adolescence: Australian Temperament Project 1983-2000. Melbourne: Australian Institute of Family Studies.

17. Sanson A, Smart D, Prior M, Oberklaid F \& Pedlow R (1994) The structure of temperament from three to seven years: age, sex and sociodemographic differences. Merrill-Palmer $Q \mathbf{4 0}$, $233-252$.
18. Department of Health, Cox A \& Bentovim A (2000) The Family Pack of Questionnaires and Scales. London: The Stationery Office.

19. Epstein NB, Baldwin LM \& Bishop DS (1983) The McMaster family assessment device. J Marital Fam Ther 9, 171-180.

20. Tamura T, Goldenberg RL, Hou J, Johnston KE, Cliver SP, Ramey SL \& Nelson KG (2002) Cord serum ferritin concentrations and mental and psychomotor development of children at five years of age. J Pediatr 140, 165-170.

21. Sawyer MG, Baghurst P \& Clark J (1992) Differences between reports from children, parents and teachers: implications for epidemiological studies. Aust N Z J Psychiatry 26, 652-660.

22. Helland IB, Smith L, Saarem K, Saugstad OD \& Drevon CA (2003) Maternal supplementation with very-long-chain $n-3$ fatty acids during pregnancy and lactation augments children's IQ at 4 years of age. Pediatrics 111, e39-e44.

23. Tamura T, Goldenberg RL, Ramey SL, Nelson KG \& Chapman VR (2003) Effect of zinc supplementation of pregnant women on the mental and psychomotor development of their children at $5 \mathrm{y}$ of age. Am J Clin Nutr 77, 1512-1516.

24. Schoetzau A, Gehring U, Franke K, Grubl A, Koletzko S, von Berg A, Berdel D, Reinhardt D, Bauer CP \& Wichmann H-E (2002) Maternal compliance with nutritional recommendations in an allergy preventive programme. Arch Dis Child 86, 180-184.

25. Daniel A (1983) Power, Privilege and Prestige: Occupations in Australia, 1st ed. Melbourne: Longman-Cheshire. 